\title{
Práticas e perspectivas dos professores das disciplinas específicas e de Matemática e dos alunos do Curso Técnico Integrado em Eletrotécnica do IFPI - Campus Teresina Central, a partir da disciplina de Circuitos Elétricos
}

\section{Practice and perspectives of Mathematics teachers and of the specific disciplines and students of the Integrated Technical Course in Electrotechnology of IFPI - Teresina Central Campus, from the discipline of Electrical Circuits}

\author{
Verônica Danielly de Oliveira (veronielly@ifpi.edu.br) \\ Instituto Federal do Piauí - IFPI \\ Ezequias Matos Esteves, (ezequias@ifpi.edu.br) \\ Instituto Federal do Piauí - IFPI
}

\begin{abstract}
Resumo: Esse artigo é resultado da dissertação de mestrado apresentada ao programa PROFMAT e teve como objetivo investigar a prática e percepções dos professores de Matemática, dos professores das disciplinas específicas e dos alunos do Curso Técnico Integrado em Eletrotécnica do IFPI - Campus Teresina Central tomando como referência a influência dos conhecimentos matemáticos na disciplina Circuitos Elétricos, e elencar diretrizes que possam contribuir para a reformulação do Projeto Político Pedagógico do Curso. Para tanto, realizou-se uma pesquisa que teve como instrumentos de coleta de dados questionários e atividades prática e teórica. Desse modo, levantaramse os pré-requisitos matemáticos das disciplinas específicas; ademais, levantou-se que o conhecimento prévio dos conteúdos pré-requisitos é relevante para a aprendizagem dos alunos. De modo que, possibilitar o estudo desses pré-requisitos, antes do estudo da disciplina específica, e promover a integração entre os professores das diversas áreas foram as diretrizes elencadas.
\end{abstract}

Palavras-chave: Técnico Integrado em Eletrotécnica; pré-requisitos matemáticos; disciplinas específicas.

\begin{abstract}
This article is the result of a master dissertation presented to the PROFMAT program and had as objective to investigate the practice and perceptions of students and the Mathematics teachers of the specific disciplines of the Integrated Technical Course in Electrotechnology from IFPI - Teresina Central Campus about the influence of mathematical knowledge in the Electrical Circuits discipline, and then to list guidelines that may contribute to the reformulation of the Political Pedagogical Project of the Course. For that, a research was conducted that had as instruments of data collection questionnaires and practical and theoretical activities. In this way, the mathematical prerequisites of the specific disciplines were raised; in addition, it was raised that the previous knowledge of the prerequisite contents is relevant for the learning of students. So, to allow the study of these prerequisites, before the study of the specific discipline,
\end{abstract}


and to promote the integration among the teachers of the different areas were the guidelines listed.

Keywords: Integrated Technical in Electrotechnology; mathematical prerequisites; specific disciplines.

\section{INTRODUÇÃO}

A educação profissional contribui para o desenvolvimento de competências e valores que serão úteis aos discentes no sentido de os mesmos terem mais oportunidade de emprego no mercado de trabalho. O decreto 5.154/04 regulamenta o $\S 2^{\circ}$ do art. $36 \mathrm{e}$ os arts. 39 a 41 da Lei $\mathrm{n}^{\circ}$ 9.394, de 20 de dezembro de 1996, que estabelece as diretrizes e bases da educação nacional e, dessa forma, propõe o ensino médio integrado à educação profissional técnica. Na visão de Araújo e Frigotto (2015), o ensino integrado se compromete com a ideia de uma formação que seja inteira e que promova o desenvolvimento de aptidões. Dessa forma, "a prática educacional desses cursos deve ser pautada na filosofia da integração, com base nos princípios de contextualidade, interdisciplinaridade e flexibilidade" (ANTONELLO et al., 2018, p. 118).

Os Parâmetros Curriculares Nacionais (PCNs) para o ensino médio, documento publicado pelo Ministério da Educação que regulamenta as competências escolares para o ensino médio, traz, em seu capítulo sobre Matemática, a necessidade de adequação do ensino dessa disciplina no ensino médio, para que haja o desenvolvimento do aluno, bem como sua promoção e inserção num mundo em mudança, contribuindo para o desenvolvimento das capacidades que lhes serão exigidas em sua vida social e profissional.

Para que a aplicação da Matemática em outras áreas e na atividade profissional seja vivida pelos alunos, faz-se necessária a contextualização entre tais áreas do saber, na busca de técnicas e estratégias pertinentes à vivência profissional e à conexão com as diversas áreas. O professor, nesse contexto, seguindo as orientações dos PCNs, tem um papel de facilitador no sentido da convergência entre a Matemática e as demais áreas.

Para Gonçalves e Pires (2014):

O encontro da Matemática com outras ciências na prática pedagógica e educacional pode ajudar o estudante a construir uma visão de mundo menos fragmentada e mais articulada, desenvolvendo a capacidade de raciocinar e 

(GONÇALVES; PIRES, 2014, p. 250).

A Resolução $n^{\circ}$ 6, de setembro de 2012, define as Diretrizes Curriculares Nacionais para a Educação Profissional Técnica de Nível Médio e traz alguns Princípios Norteadores, de acordo com essa resolução, as bases para os planejamentos dos cursos e programas são os Catálogos Nacionais de Cursos mantidos pelo MEC.

O Catálogo Nacional de Cursos Técnicos (CNCT), documento elaborado pelo Ministério da Educação, serve para dar orientações às instituições, aos estudantes e à sociedade no que diz respeito à oferta de cursos de educação profissional técnica de nível médio. Dessa forma, contribui para o planejamento dos cursos, qualificações profissionais correspondentes e especializações técnicas de nível médio.

É necessário que os conhecimentos do curso técnico integrado tenham sido apreendidos de forma significativa, ou seja, que, após a conclusão do curso, os concludentes realmente tenham base para exercer a profissão, saibam utilizar o que viram no exercício da profissão e não simplesmente reproduzir dados que tenham memorizado. Dessa forma, "o conhecimento científico abordado em sala de aula deve adquirir significados para o aluno, a fim de que ele possa transpor esse aprendizado para o seu cotidiano”. (DARROZ et al., 2015, p. 70).

Para uma melhor compreensão do processo de aquisição do conhecimento, é necessário que se entenda o que é aprendizagem significativa, uma teoria proposta por David Ausubel (1918-2008) em 1963. Ausubel graduou-se em Psicologia e Medicina, fez doutorado em Psicologia do Desenvolvimento na Universidade de Columbia, foi professor no Teachers College tendo dedicado sua vida acadêmica ao desenvolvimento de uma visão cognitiva da Psicologia Educacional (MOREIRA, 2012). Para Moreira (2011, p. 13), “aprendizagem significativa é aquela em que ideias expressas simbolicamente interagem de maneira substantiva e não-arbitrária com aquilo que o aprendiz já sabe". Segundo a teoria da aprendizagem significativa, perceber aquilo que o aluno já sabe é muito relevante, pois as novas informações irão interagir com os conhecimentos já adquiridos pelo aluno.

No contexto do aprendizado de um aluno do ensino médio integrado, a interação entre os conhecimentos prévios e os conhecimentos novos conduz a novos significados 
para os primeiros, ou seja, é necessário que o aluno já tenha algum conhecimento que possa interagir com o conteúdo novo a ser aprendido, e essa interação resultará em uma assimilação do novo e também em uma ressignificação do que ele já possuía. Dessa forma, "a aprendizagem significativa ocorre quando o aprendiz consegue atribuir significado ao que está sendo aprendido, porém estes significados têm sempre atributos pessoais" (MORAES; SILVA JÚNIOR, 2014, p. 62).

A importância dos conhecimentos prévios fica evidente, pois "a interação entre as novas ideias apresentadas e as ideias relevantes existentes (ancoradas), permite que o significado das primeiras surja como um produto dessa interação" (SOUSA et al., 2015, p. 714). E, no caso do ensino médio integrado ao técnico, faz-se necessário pensar em possibilidades que conduzam a uma integração entre as diversas áreas do conhecimento, pois, dessa forma, as disciplinas que possuam em sua ementa conteúdos que tenham pré-requisitos de outras disciplinas encontrarão um suporte.

Assim, antes de se pensar em como preparar a inserção de um novo conteúdo de uma disciplina, convém procurar saber quais conhecimentos prévios são necessários e, dessa forma, sondar o que os alunos sabem sobre eles. Nesse contexto, a teoria da aprendizagem significativa "tem um papel relevante no que tange à formação dos estudantes, tendo em vista os desafios impostos pela atual sociedade, pois ela auxilia os professores no processo de ensino" (SILVA; SCHIRLO, 2014, p. 42). Sendo assim, "as experiências e os conhecimentos prévios dos alunos devem ser evocados na busca da aprendizagem significativa" (BOLLELA et al., 2014, p. 294).

Com o intuito de pesquisar sobre os conhecimentos e influências da Matemática no Curso Técnico em Eletrotécnica Integrado ao Médio, o presente trabalho se propôs pesquisar sobre a matemática presente nas disciplinas específicas do curso, em especial na de Circuitos Elétricos. Para tanto, foi utilizada uma abordagem prática e teórica com os alunos, por meio de atividades, aplicação de questionários aos alunos e professores com o intuito de obter respostas para o seguinte questionamento: como a Matemática proposta e ensinada nas disciplinas propedêuticas de Matemática do ensino médio está relacionada com as disciplinas específicas do Curso Técnico Integrado em Eletrotécnica do IFPI - Campus Teresina Central, em particular com a disciplina Circuitos Elétricos, 
e quais diretrizes podem ser elencadas para contribuir para a reformulação do Projeto Político Pedagógico do Curso?

Então, o objetivo geral da presente pesquisa é investigar a prática e percepções dos professores de Matemática, dos professores das disciplinas específicas e dos alunos do Curso Técnico Integrado em Eletrotécnica do IFPI - Campus Teresina Central tomando como referência a influência dos conhecimentos matemáticos na disciplina Circuitos Elétricos e elencar diretrizes que possam contribuir para a reformulação do Projeto Político Pedagógico do Curso.

Para isso, foram traçados os seguintes objetivos específicos: fazer um levantamento da matemática presente nas disciplinas específicas do Curso Técnico em Eletrotécnica Integrado ao Médio, do IFPI-Campus Teresina Central, em especial na disciplina Circuitos Elétricos, com o intuito de analisar quais conteúdos matemáticos do ensino médio são pré-requisitos para tal disciplina; mapear as percepções e conhecimentos dos alunos no que diz respeito à relação entre a Matemática até então estudada e a disciplina Circuitos Elétricos e avaliar o nível de integração entre os professores das disciplinas específicas e os professores de Matemática à luz da proposta do PPC do Curso de Eletrotécnica.

\section{METODOLOGIA}

A pesquisa foi realizada no Instituto Federal do Piauí - IFPI, Campus Teresina Central. Participaram da pesquisa professores das disciplinas específicas dos cursos de Eletrotécnica e Eletrônica e professores de Matemática, além de 28 alunos do segundo ano do ensino médio do curso de Eletrotécnica. Em se tratando de ambiente, a pesquisa com os alunos utilizou a sala de aula e o laboratório de Eletrônica. A sala de aula foi utilizada para a realização de uma atividade teórica e a aplicação de um questionário com os alunos; já o laboratório foi utilizado para a realização de uma atividade prática.

Para a obtenção dos dados, inicialmente foi feito um estudo bibliográfico. $\mathrm{O}$ intuito dessa etapa foi adquirir conhecimento, pois o estudo da literatura "representa uma fonte indispensável de informações, podendo até orientar as indagações" (LAKATOS; MARCONI, 2003, p.158). Dessa forma, segundo Lakatos e Marconi (2003), se houver por parte do pesquisador um bom aproveitamento dos dados obtidos, 
haverá a possibilidade da descoberta de subsídios ou indícios que sejam importantes para o trabalho.

De posse do conhecimento adquirido através do estudo bibliográfico, foram elaborados alguns instrumentos a serem utilizados na coleta dos dados. Optou-se pela realização de questionários com os professores das disciplinas específicas, com os professores de Matemática e com os alunos.

Além de também responderem ao questionário, os alunos desenvolveram atividades prática e teórica. A atividade prática foi realizada no laboratório de Eletrônica, onde tinham disponíveis oito bancadas para realização de atividades práticas, das quais continham: um osciloscópio, que é um instrumento capaz de medir sinais elétricos e registrar gráficos; um gerador de sinais (ou gerador de funções), que é um equipamento capaz de gerar sinais elétricos em forma de onda, frequência e amplitude selecionáveis; e cabos de conexão.

A atividade teórica foi realizada na sala de aula com 20 do total de alunos participantes da pesquisa. O objetivo dessa atividade era que os alunos analisassem um circuito elétrico e identificassem os conteúdos matemáticos presentes. O circuito era do tipo RLC série, ou seja, havia um resistor (R), um indutor (L) e um capacitor (C) conectados em série, além da fonte de tensão alternada.

\section{RESULTADOS E DISCUSSÃO}

\subsection{ANÁLISE DAS RESPOSTAS DO QUESTIONÁRIO APLICADO AOS ALUNOS}

Objetivando mapear as percepções e conhecimentos dos alunos no que diz respeito à relação entre a Matemática até então estudada e as disciplinas específicas, em especial a disciplina Circuitos Elétricos, aplicou-se um questionário com os alunos da turma escolhida. Dos 21 alunos que entregaram o questionário respondido, 57\% eram do sexo masculino e $43 \%$ eram do sexo feminino; as idades variaram de 15 a 18 anos.

O Quadro 1 traz a síntese das respostas dadas pelos alunos à seguinte pergunta: Levando em conta os conteúdos estudados nas disciplinas específicas do seu curso de Eletrotécnica, e os conteúdos matemáticos que lhe foram necessários para uma melhor compreensão do conhecimento abordado nas disciplinas específicas, preencha o quadro. 
Vol. 2, n. 2. Mai./Ago. 2019

Quadro 1 - Pré-requisitos matemáticos das disciplinas específicas apontados pelos alunos

\begin{tabular}{|c|c|c|}
\hline $\begin{array}{l}\text { Nome da disciplina } \\
\text { específica }\end{array}$ & $\begin{array}{c}\text { Conteúdos da } \\
\text { disciplina específica que } \\
\text { necessitam de pré-requisitos } \\
\text { matemáticos }\end{array}$ & $\begin{array}{c}\text { Conteúdos } \\
\text { matemáticos necessários à } \\
\text { disciplina específica }\end{array}$ \\
\hline Eletricidade & $\begin{array}{ll}\text { - } & \text { Cargas elétricas } \\
\text { - } & \text { Lei de Ohm }\end{array}$ & $\begin{array}{ll}\text { - } & \text { Equações de } 1^{\circ} / 2^{\circ} \text { graus } \\
\text { - } & \text { Fração } \\
\text { subtração) } & \text { (soma, } \\
\text { - } & \text { Matemática básica }\end{array}$ \\
\hline Medidas Elétricas & $\begin{array}{ll}\text { - } & \text { Transformadores } \\
\text { - } & \text { Simbologia }\end{array}$ & $\begin{array}{l}\text { - } \begin{array}{l}\text { Fração, radiciação, } \\
\text { potenciação }\end{array} \\
\text { - } \text { Geometria } \\
\text { - } \text { Matemática básica }\end{array}$ \\
\hline Eletrônica Digital & $\begin{array}{ll}\text { - } & \text { Lógica de Boole } \\
\text { - } & \text { Portas lógicas } \\
\text { - } & \text { Números binários }\end{array}$ & $\begin{array}{ll}\text { - } & \text { Lógica } \\
\text { - } & \text { Análise combinatória }\end{array}$ \\
\hline Máquinas Elétricas & $\begin{array}{ll}\text { - } & \text { Transformadores } \\
\text { - } & \text { Estudo das máquinas } \\
\text { - } & \text { Eletromagnetismo } \\
\text { - } & \text { Motor CC } \\
\text { - } & \text { Geradores }\end{array}$ & $\begin{array}{ll}\text { - } & \text { Fração, radiciação } \\
\text { - } & \text { Equações do } 1^{\circ} \text { e } 2^{\circ} \\
\text { graus } & \\
\text { - } & \text { Trigonometria } \\
\text { - } & \text { Notação científica }\end{array}$ \\
\hline $\begin{array}{l}\text { Desenho Auxiliado por } \\
\text { Computador }\end{array}$ & $\begin{array}{ll}\text { - } & \text { Dimensionamento } \\
\text { elétrico } \\
\text { - } & \text { Memorial de cargas } \\
\text { - } & \text { Planta baixa } \\
\end{array}$ & $\begin{array}{ll}\text { - } & \text { Área de polígonos } \\
\text { - } & \text { Formas geométricas } \\
\text { - } & \text { Perimetria }\end{array}$ \\
\hline Circuitos Elétricos & $\begin{array}{l}\text { - } \quad \text { Circuitos mistos } \\
\text { - } \quad \text { Ondas senoidais } \\
\text { - } \quad \text { Impedância complexa } \\
\text { - } \quad \text { Resolução de Circuitos } \\
\text { - } \quad \text { Corrente Alternada } \\
\text { - } \quad \text { Circuitos resistivos, RL, } \\
\quad \text { RC e RLC (série e } \\
\text { paralelo) }\end{array}$ & $\begin{array}{ll}\text { - } & \text { Números Complexos } \\
\text { - } & \text { Trigonometria } \\
\text { - } & \text { Potenciação } \\
\text { - } & \text { Radiciação }\end{array}$ \\
\hline Eletrônica Básica & $\begin{array}{ll}\text { - } & \text { Ondas senoidais } \\
\text { - } & \text { Diodos } \\
\text { - } & \text { Análise de circuitos }\end{array}$ & $\begin{array}{ll}\text { - } & \text { Função seno } \\
\text { - } & \text { Cálculos simples } \\
\text { - } & \text { Análise de gráficos } \\
\text { - } & \text { Matemática básica } \\
\text { - } & \text { Trigonometria }\end{array}$ \\
\hline Instalações Elétricas & $\begin{array}{l}\text { - Instalação de plantas, } \\
\text { medidas. }\end{array}$ & - Geometria \\
\hline
\end{tabular}

Fonte: A própria autora, com base nos dados colhidos na pesquisa, 2019.

Ao analisar as ementas das disciplinas de Matemática do $1^{\circ}$ e $2^{\circ}$ anos, verificou-se que alguns conteúdos apontados pelos alunos não foram vistos antes do estudo na disciplina específica ou foram vistos concomitantemente com a disciplina específica. Além disso, muitos pré-requisitos matemáticos apontados são conteúdos do ensino fundamental, como, por exemplo, fração, soma, subtração, radiciação, potenciação, entre outros. 
Com a seguinte pergunta: De acordo com o que você estudou na disciplina Circuitos Elétricos, você acha que é necessário o conhecimento de alguns conteúdos matemáticos para um bom desempenho na disciplina?, buscou-se a percepção dos alunos com relação a pré-requisitos matemáticos para a disciplina Circuitos Elétricos. Os alunos foram unânimes ao concordar que é necessário o conhecimento de alguns conteúdos matemáticos para o bom entendimento da disciplina Circuitos Elétricos. Em suas justificativas, eles pontuaram alguns conteúdos, como, por exemplo, números complexos e função seno. Vale destacar que, de acordo com as ementas presentes no PPC, o conteúdo de números complexos, pertencente à ementa da disciplina Circuitos Elétricos, é visto na disciplina Matemática do terceiro ano, portanto, depois de eles terem estudado Circuitos Elétricos, que é do segundo ano.

\subsection{ANÁLISE DAS RESPOSTAS DOS QUESTIONÁRIOS APLICADOS AOS PROFESSORES}

Com o intuito de mapear os pré-requisitos matemáticos das disciplinas específicas do Curso Integrado em Eletrotécnica e, além disso, investigar o nível de interação entre os professores de Matemática e os professores das disciplinas específicas, foi aplicado um questionário aos professores das disciplinas específicas e com os professores de Matemática. Para discussão dos resultados apresentados nos questionários aplicados aos professores, primeiramente serão analisadas as respostas dadas pelos professores das disciplinas específicas e depois as respostas dadas pelos professores de Matemática.

\subsubsection{Professores das disciplinas específicas}

Para conhecimento do perfil dos professores, foram introduzidas, no questionário, duas perguntas que objetivaram saber o sexo e o nível de formação do professor. Os 11 professores que responderam ao questionário são do sexo masculino e os dados referentes à suas formações encontram-se na Figura 1. 
Vol. 2, n. 2. Mai./Ago. 2019

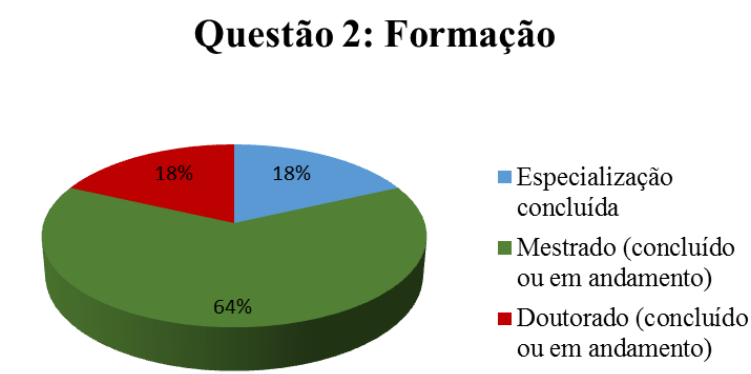

Figura 1 - Dados sobre a formação dos professores das disciplinas específicas

De acordo com a Figura 1, a maioria dos professores, ou seja, 64\% possuem mestrado concluído ou em andamento, outros $18 \%$ possuem especialização concluída e também $18 \%$ possuem doutorado concluído ou em andamento. Alguns informaram a área da pós-graduação, outros não. As áreas informadas foram: Engenharia dos Materiais, Desenvolvimento e Meio-Ambiente e Engenharia Elétrica.

Na seguinte pergunta: Como você acha que os professores de Matemática das turmas do Médio Integrado em Eletrotécnica devem trabalhar os conteúdos matemáticos?, somente um professor não respondeu. Os outros todos $(91 \%)$ foram unânimes ao considerar que seria conveniente que os professores de Matemática do curso Técnico Integrado em Eletrotécnica contextualizassem os conteúdos de Matemática com a área do curso.

Na seguinte pergunta: Qual a sua relação com os professores de Matemática das turmas para as quais você leciona as disciplinas específicas?, somente o professor PE7 afirmou ter um diálogo com o professor de Matemática. Ele respondeu: "Sempre no início do período letivo, converso com o professor da área de matemática para que o desenvolvimento da disciplina transcorra dentro da normalidade e o aluno tenha mais facilidade no aprendizado." O professor considera que esse diálogo pode ocasionar uma facilidade no aprendizado do aluno. Já os demais professores, ou seja, 91\% dos pesquisados afirmaram não haver nenhuma relação com os professores de Matemática das turmas que lecionam. O professor PE6 sugere a capacitação dos professores de Matemática na área do curso.

Na seguinte pergunta: No decorrer do ano letivo, há algum planejamento entre os professores das disciplinas específicas e os das propedêuticas no sentido de se buscarem estratégias para que ocorra uma integração entre as diversas áreas? 
Como você acha que tais estratégias poderiam ser buscadas?, somente o professor PE7 afirmou haver planejamento nesse sentido. Ele respondeu: "Sempre há esse planejamento para que as estratégias de ensino sejam convergentes". Os demais professores, ou seja, $91 \%$ dos pesquisados afirmaram não haver esse planejamento e sugeriram ações a serem realizadas para se buscar a integração entre as áreas. A sugestão mais frequente foi a realização de reuniões para que todos os professores participassem.

O professor PE2 afirmou haver um momento de planejamento no início do ano, no entanto, sem efetividade e objetividade, e sugeriu: "deveria ser um momento mais bem preparado e objetivo onde de fato houvesse solução para os problemas".

$\mathrm{O}$ Quadro 2 traz a síntese das respostas dadas pelos professores à seguinte pergunta: Levando em conta as disciplinas que você ministra ou já ministrou e os conteúdos matemáticos que lhe foram necessários para dar uma melhor compreensão do conhecimento abordado na disciplina, preencha o quadro abaixo.

Quadro 2: Pré-requisitos matemáticos das disciplinas específicas apontados pelos professores dessas disciplinas

\begin{tabular}{|c|c|c|}
\hline $\begin{array}{c}\text { Nome da } \\
\text { disciplina específica }\end{array}$ & $\begin{array}{c}\text { Conteúdos da disciplina } \\
\text { específica que necessitam de pré- } \\
\text { requisitos matemáticos }\end{array}$ & $\begin{array}{c}\text { Conteúdos } \\
\text { matemáticos necessários à } \\
\text { disciplina específica }\end{array}$ \\
\hline
\end{tabular}


Vol. 2, n. 2. Mai./Ago. 2019

\begin{tabular}{|c|c|c|}
\hline Eletricidade & $\begin{array}{ll}\text { - } & \text { Eletricidade } \\
\text { - } & \text { Associação } \\
& \text { resistores/capacitores/indutores } \\
\text { - } & \text { Eletrostática } \\
\text { - } & \text { Eletrodinâmica } \\
\text { - } & \text { Circuitos Elétricos } \\
\text { - } & \text { Carga e descarga de capacitores } \\
\text { - Leis de Kirchhoff } \\
\text { - Lei de Coulomb } \\
\text { - Lei de Ohm }\end{array}$ & $\begin{array}{l}\text { - Regra de três } \\
\text { - Proporção } \\
\text { - } \text { Equações do } 1^{\circ} \text { grau } \\
\text { - Potenciação } \\
\text { - } \text { Divisão, soma, subtração } \\
\text { - Números fracionários } \\
\text { - Sistemas de equações } \\
\text { - Potência de dez } \\
\text { - Funções afim, quadrática e } \\
\quad \text { exponencial. }\end{array}$ \\
\hline Medidas Elétricas & $\begin{array}{l}\text { - Medidas eletrônicas } \\
\text { - Parâmetros de medidas em sinais de } \\
\text { ondas periódicas } \\
\text { - Cálculo de parâmetros elétricos: } \\
\text { - tensão, corrente, potência, resistência. } \\
\text { - Análise de circuitos }\end{array}$ & $\begin{array}{l}\text { - } \text { Regra de três } \\
\text { - } \text { Proporção } \\
\text { - } \text { Equações de } 1^{\circ} / 2^{\circ} \text { graus } \\
\text { - Plano cartesiano } \\
\text { - Notação científica, ordem de } \\
\text { grandeza. } \\
\text { - Algarismos significativos } \\
\text { - Números complexos } \\
\text { - Trigonometria } \\
\end{array}$ \\
\hline Eletrônica Digital & $\begin{array}{l}\text { - Álgebra de Boole } \\
\text { - Sistemas de Numeração } \\
\text { - Portas lógicas }\end{array}$ & $\begin{array}{ll}\text { - } & \text { Potenciação } \\
\text { - } & \text { Equações do } 1^{\circ} \text { grau } \\
\text { - } & \text { Multiplicação e divisão } \\
\text { - } & \text { Lógica } \\
\end{array}$ \\
\hline Máquinas Elétricas & - Campo magnético & - Radiciação \\
\hline Eletrônica Industrial & - Potências ativa, reativa, aparente & - Onda senoidal \\
\hline Circuitos Elétricos & $\begin{array}{l}\text { - Grandezas senoidais } \\
\text { - Análise de circuitos } \\
\text { - Fasores }\end{array}$ & $\begin{array}{l}\text { - Números complexos } \\
\text { - Trigonometria } \\
\text { - Potenciação } \\
\text { - Radiciação } \\
\text { - Plano cartesiano }\end{array}$ \\
\hline Eletrônica Básica & $\begin{array}{ll}\text { - } & \text { Circuitos eletrônicos } \\
\text { - } & \text { Diodos, transistores } \\
\text { - } & \text { Retificadores }\end{array}$ & $\begin{array}{ll}\text { - } & \text { Regra de três } \\
\text { - } & \text { Proporção } \\
\text { - } & \text { Equações de } 1 \% 2^{\circ} \text { graus } \\
\text { - } & \text { Potência de dez } \\
\text { - } & \text { Sistemas lineares }\end{array}$ \\
\hline $\begin{array}{ll}\text { Instalações } & \text { Elétricas } \\
\text { Prediais } & \end{array}$ & $\begin{array}{l}\text { - Problema de compatibilidade de } \\
\text { grandezas elétricas }\end{array}$ & - Equações do $1^{\circ}$ grau \\
\hline $\begin{array}{l}\text { Instalações } \quad \text { Elétricas } \\
\text { Industriais }\end{array}$ & - Correção do fator de potência & - Números complexos \\
\hline Fontes Alternativas & - Operações algébricas & - Problemas algébricos \\
\hline
\end{tabular}

Fonte: A própria autora, com base nos dados colhidos na pesquisa, 2019.

É possível observar pré-requisitos matemáticos que nas disciplinas de Matemática são estudados após ou simultaneamente aos conteúdos das disciplinas específicas que necessitam desses pré-requisitos. Como, por exemplo, Números Complexos que pertence à ementa de Matemática do terceiro ano e Trigonometria que pertence à 
ementa de Matemática do segundo ano. Assim como no quadro síntese das respostas dos alunos, no quadro síntese das respostas dos professores, há muitos pré-requisitos matemáticos do ensino fundamental.

\subsubsection{Professores de Matemática}

Quatro professores deram retorno com o questionário respondido, no entanto, um deles nunca lecionou no ensino médio integrado e, portanto, não se considerou suas respostas. Os três professores considerados são do sexo masculino. O professor PM1 possui Mestrado Profissional em Matemática (PROFMAT), o professor PM2 possui Especialização em Metodologia do Ensino de Matemática e Física e o professor PM3 é Mestre em Equações Diferenciais (análise).

Ao serem perguntados: Ao trabalhar com o integrado, qual a sua relação com os professores das disciplinas específicas do curso?, o professor PM1 respondeu: "Conheço vários professores da área específica e com alguns faço integração entre as áreas", como ele não citou de qual curso são esses professores, não é possível fazer um confronto com as respostas dos professores das disciplinas específicas.

O professor PM2 respondeu: "Existe pouco contato com os professores específicos do curso." E o professor PM3 respondeu: "Quase nenhuma." O que corrobora as respostas da maioria dos professores das disciplinas específicas.

$\mathrm{Na}$ seguinte pergunta: Em algum momento, ao trabalhar no integrado, há algum planejamento onde os professores de Matemática e os professores das disciplinas específicas possam interagir em busca da integração entre as áreas? Como você acha que tal integração poderia ser alcançada?, o professor PM1 respondeu: "Não há esse planejamento. Seria interessante se ocorresse." O professor PM2 confirmou: "Não existe uma integração de planejamento entre os professores de matemática e os professores específicos do curso. Os planejamentos são feitos separados." O professor PM3 também deu resposta semelhante à dos primeiros: "Não há essa interação entre os professores no planejamento, algumas vezes quando existe é somente entre professores de uma mesma área”.

$\mathrm{Na}$ seguinte pergunta: Como você acha que os professores de Matemática devem trabalhar a integração com as áreas de cada curso técnico?, o professor PM1 
respondeu: "Buscando conhecer a aplicação matemática dentro de cada curso e, planejando com os professores das disciplinas específicas a relação entre os conteúdos ministrados.” O professor PM2 opinou: “Em planejamentos e reuniões em princípio seria o primeiro passo.” E o professor PM3 sugeriu:

Primeiro precisamos conhecer a natureza de cada curso e tentar adequar nossas aulas aos conhecimentos técnicos daquele curso, e isso seria bem mais fácil se houvesse uma integração maior entre os professores das diversas áreas do conhecimento.

\section{3 ANÁLISE DA ATIVIDADE PRÁTICA}

Com o objetivo de mapear os conteúdos matemáticos envolvidos na análise de sinais senoidais, conteúdo da disciplina de Circuitos Elétricos, e a percepção dos alunos quanto à forma de abordagem desses conteúdos, realizou-se uma atividade prática com a turma escolhida. Os alunos utilizaram um gerador de sinais para obter uma onda senoidal e registrá-la no osciloscópio. Após a aferição no osciloscópio, os alunos responderam a algumas questões.

A Figura 2 mostra o esboço do gráfico aferido no osciloscópio feito pelo aluno AP18.

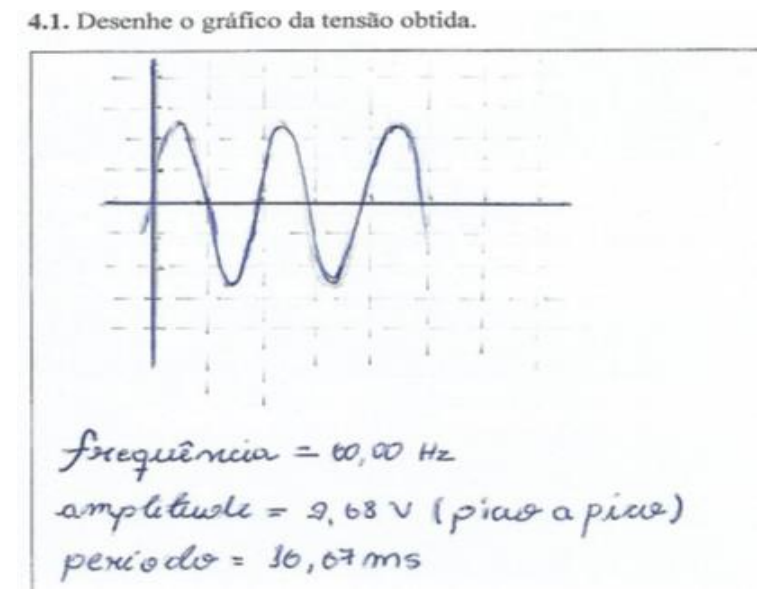

Figura 2 - Esboço do gráfico do sinal senoidal aferido no osciloscópio

O aluno AP18 fez o esboço do gráfico que aferiu no osciloscópio e forneceu a frequência em $\mathrm{Hz}$, a amplitude de pico a pico e o período. 
Após a realização do esboço do gráfico do sinal senoidal, os alunos responderam:

O gráfico desenhado anteriormente é semelhante ao gráfico de alguma função que você estudou em Matemática? Qual função? Aponte as semelhanças, caso sua resposta tenha sido sim. Os alunos foram unânimes ao afirmar que já haviam estudado em Matemática uma função cujo gráfico se assemelha ao gráfico que eles aferiram no osciloscópio e apontaram a função seno. Alguns também apontaram, além da função seno, a função cosseno. O aluno AP22 respondeu: "Sim. Função seno. Ela começa a partir do $0^{\circ}$, a diferença é que a amplitude de pico a pico é diferente, no seno é 2 e na atividade é 10." Averiguou-se que todos os alunos conseguiram relacionar um gráfico obtido em atividade prática a um conteúdo estudado na disciplina de Matemática e além disso apontaram semelhanças e diferenças.

Na seguinte pergunta: Caso tenha relacionado o gráfico que você desenhou com o gráfico de alguma função, responda se você estudou tal função na disciplina de Matemática antes ou depois de ter estudado sinais senoidais na disciplina Circuitos Elétricos. Você acha que foi adequada a forma como tais conteúdos foram abordados em cada disciplina com relação ao período (tempo)?, os alunos foram unânimes ao responder que estudaram a função seno em Matemática depois de terem estudado sinais senoidais na disciplina Circuitos Elétricos. O aluno AP10 respondeu que a forma foi adequada, pois “de qualquer jeito veríamos o assunto”, mas os demais alunos responderam não ter sido adequada a forma como os conteúdos foram abordados, ou seja, não foi o formato ideal a função seno ter sido estudada em Matemática após o estudo de sinais senoidais na disciplina Circuitos Elétricos.

$\mathrm{Na}$ seguinte pergunta: Independente de onde tenha visto primeiro o conteúdo, ao estudar pela segunda vez, foi possível relacioná-lo com o primeiro? Caso esteja estudando pela segunda vez, qual o impacto que isso gerou na sua aprendizagem?, os alunos foram unânimes ao responder que foi possível relacionar o conteúdo que estudaram por último com o conteúdo que já haviam estudado, ou seja, ao estudarem funções trigonométricas na disciplina Matemática, eles relacionaram com sinais senoidais já estudado na disciplina Circuitos Elétricos.

\subsection{ANÁLISE DA ATIVIDADE TEÓRICA}


Visando pesquisar quais conteúdos matemáticos os alunos eram capazes de identificar na análise de um circuito estudado na disciplina Circuitos Elétricos, os alunos realizaram uma atividade teórica.

$\mathrm{Na}$ seguinte questão: De acordo com o que você estudou na disciplina Circuitos Elétricos, para o circuito a seguir, obtenha..., os alunos analisaram um circuito RLC série e identificaram algumas grandezas. A figura 3 mostra o circuito analisado.

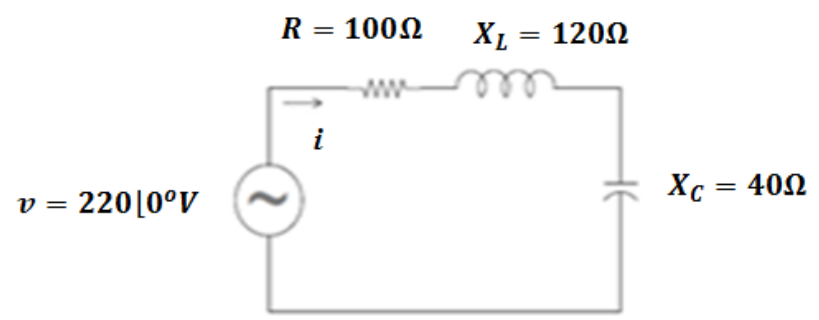

Figura 3 - Circuito RLC série da atividade teórica

O item "a" solicitou: a impedância complexa (módulo e fase). Na resolução do item desse item, feita pelo aluno AT17, observou-se que ele representou a impedância complexa por meio de um número complexo na forma cartesiana; utilizou a fórmula $Z=R+j\left(X_{L}-X_{C}\right)$, dessa forma ele encontrou $Z=100+j 80$ e depois a obteve na forma polar $(Z=\|Z\| \emptyset)$, chegando a $Z=128,06\left[38,66^{\circ} \Omega\right.$, e, para isso, utilizou o teorema de Pitágoras para obter o módulo da impedância $(\|Z\|)$ e trigonometria para obter a fase (ângulo) (Ø). (Ø) é um ângulo para um dado valor da tangente; neste caso, o valor da tangente é 0,8 .

A Figura 4 mostra a resolução dos demais itens da análise do circuito feita pelo aluno AT20. 
b) A comente complexa (i)

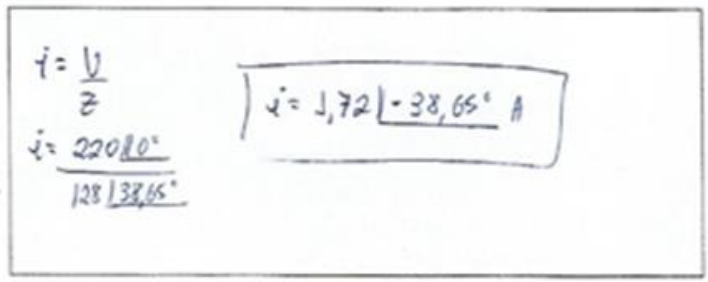

c) A tensio no ressistor $\left(v_{R}\right)$.

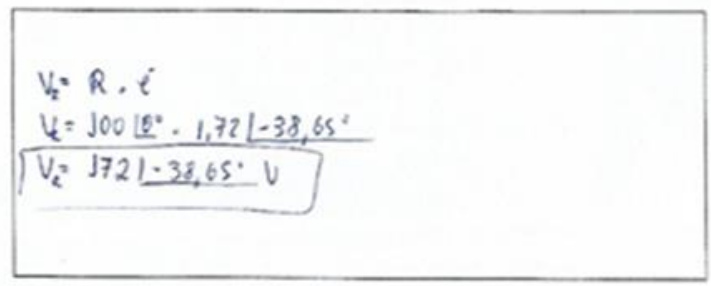

d) A tensšo no indutor $\left(v_{l}\right)$

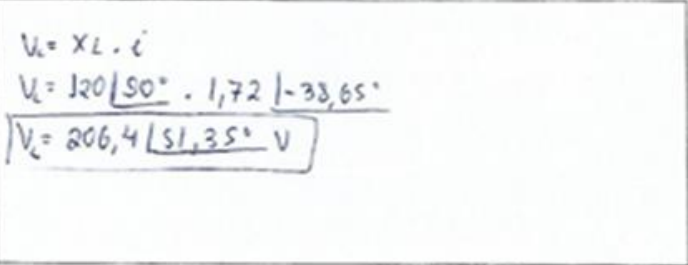

e) A tension no capacitor $\left(v_{c}\right)$.

$$
V_{1}=x_{1} \cdot i
$$

$V=401-50^{\circ} \cdot 1,721-3865^{\circ}$

$V_{c}=68,8+128,65^{\circ} \mathrm{V}$

Figura 4 - Resolução feita pelo aluno AT20

Observa-se, na resolução do item "b", que o aluno AT20 realizou uma divisão entre a tensão e a impedância, ambas representadas por um número complexo na forma polar, para encontrar a corrente complexa. Já nos itens seguintes, o aluno realizou operações de multiplicação de números complexos na forma polar para obter as tensões pedidas e também as encontrou na forma polar.

\subsection{RESPOSTAS AOS OBJETIVOS TRAÇADOS}

Os Quadros 1 e 2 trazem uma listagem dos pré-requisitos matemáticos das disciplinas específicas na visão dos alunos pesquisados e dos professores das disciplinas específicas, respectivamente. Muitos pré-requisitos apontados pelos alunos e pelos professores são conteúdos de Matemática do ensino fundamental.

$\mathrm{Na}$ atividade prática, todos os alunos relacionaram o sinal senoidal que aferiram no osciloscópio com a função seno e, na atividade teórica, os alunos apontaram números complexos, trigonometria, geometria (teorema de Pitágoras) e operações básicas, como conteúdos presentes na análise do circuito proposto na atividade.

Levou-se em conta que, entre os pré-requisitos apontados pelos participantes da pesquisa, muitos conteúdos são do ensino fundamental e elencou-se a seguinte diretriz: 
$\checkmark$ A possibilidade de os alunos revisarem conteúdos do ensino fundamental no primeiro ano.

Tal revisão poderia ocorrer por meio de um projeto de extensão a ser realizado no contra turno, visto que "as atividades de extensão contribuem para aproximar a teoria da realidade e favorecem o desenvolvimento do senso crítico do aprendiz" (CARVALHO et al., 2015, p. 191).

Levou-se em conta o fato de os conteúdos de Trigonometria e Números Complexos terem sido levantados como pré-requisitos das disciplinas Eletrônica Básica e Circuitos Elétricos, ambas do segundo ano, portanto, elencou-se a seguinte diretriz:

$\checkmark$ na reformulação do PPC do curso, sejam inseridos os conteúdos Trigonometria e Números Complexos na disciplina Matemática do primeiro ano.

Por fim, tendo em vista a importância do diálogo entre os professores de Matemática e os professores das disciplinas específicas e levando em conta a importância da contextualização entre as diversas áreas do conhecimento no processo de aprendizagem dos alunos, sugere-se que:

$\checkmark$ ocorram planejamentos entre os professores das disciplinas específicas e os professores de Matemática para que busquem a integração entre a Matemática e a área do curso.

\section{CONSIDERAÇÕES FINAIS}

De início constatou-se a necessidade de investigações que fornecessem diretrizes para o proveito do conhecimento dos alunos do curso Técnico Integrado em Eletrotécnica, pois o egresso do curso tem a possibilidade de prosseguir com estudos superiores e/ou ingressar no mercado de trabalho. Dessa forma, é fundamental que o mesmo tenha adquirido um conhecimento significativo daquilo que estudou. A proposta, então, foi pesquisar sobre os conteúdos matemáticos que são pré-requisitos das disciplinas específicas do curso.

Diante disso, a pesquisa teve como objetivo geral investigar a prática e as percepções dos professores de Matemática, dos professores das disciplinas específicas e dos alunos do Curso de Eletrotécnica do IFPI - Campus Teresina Central tomando como referência a influência dos conhecimentos matemáticos na disciplina Circuitos 
Elétricos, para então elencar diretrizes que possam contribuir para a reformulação do Projeto Político Pedagógico do Curso. Verificou-se que o objetivo foi atendido uma vez que se levantaram os conteúdos matemáticos que são pré-requisitos para as disciplinas específicas e, particularmente, para a disciplina Circuitos Elétricos na visão dos alunos e dos professores envolvidos na pesquisa. A partir dos resultados apurados, elencaram-se algumas diretrizes que podem contribuir para o aprendizado dos alunos através da reformulação do PPC do curso.

\section{REFERÊNCIAS}

ANTONELlO, S. B.; MARASCHIN, M. S.; GARCIA, I. K.; SANATROSA, M. C. P. Ensino médio integrado como alternativa para o ensino médio: experiências de um curso técnico em eletrotécnica. Vivências, v. 14, n. 27, p. 114-128, out/2018.

ARAÚJO, R. M. L.; FRIGOTTO, G. Práticas pedagógicas e ensino integrado. Revista Educação em Questão, v. 52, n. 38, p. 61-80, 15 ago. 2015.

BOLlELA, V. R.; SENGER, M. H.; TOURINHO, F. S. V.; AMARAL, E. Aprendizagem baseada em equipes: da teoria à prática. Medicina (Ribeirão Preto), 2014, 47(3): 293-300.

BRASIL. Ministério da Educação. Secretaria de Educação Média e Tecnológica. Parâmetros curriculares nacionais (Ensino Médio) - Ciências da Natureza, Matemática e suas tecnologias. Brasília, 2000.

BRASIL. Decreto n. 5.154, de 23 de julho de 2004. Regulamenta o $\S 2^{\circ}$ do art. 36 e os art. 39 a 41 da Lei n. 9.394, de 20 de dezembro de 1996, que estabelece as diretrizes e bases da educação nacional, e dá outras providências. Brasília/DF: 2004.

BRASIL. Resolução no 6, de 20 de setembro de 2012. Define Diretrizes Curriculares Nacionais para a Educação Profissional Técnica de Nível Médio. Brasília/DF: 2012.

BRASIL. Ministério da Educação. Catálogo Nacional de Cursos Técnicos. 3. ed. Brasília-DF: MEC-SETEC, 2014.

CARVALHO, D. P. S. R. P. et al. Teoria da aprendizagem significativa como proposta para inovação no ensino de enfermagem: experiência dos estudantes. Revista de Enfermagem da UFSM, [S.1.], v. 5, n. 1, p. 186 - 192, abr. 2015. ISSN 2179-7692.

DARROZ, L. M.; ROSA, C. W.; GHIGGI, C. M. Método tradicional x aprendizagem significativa: investigação na ação dos professores de física. Aprendizagem Significativa em Revista/Meaningful Learning Review, v. 5(1), pp. 70-85, 2015. 
GONÇALVES, H.J. L.; PIRES, C.M.C. Educação Matemática na Educação Profissional de Nível Médio: análise sobre possibilidades de abordagens interdisciplinares. Boletim de Educação Matemática - Bolema, Rio Claro (SP), v. 28, n. 48 , p. 230-254, abr. 2014.

LAKATOS, E. M.; MARCONI, M. A. Fundamentos de metodologia científica. 5. ed. São Paulo: Atlas, 2003.

MORAES, J.U.P.; SILVA JÚNIOR, R.S. Experimentos didáticos no ensino de Física com foco na aprendizagem significativa. Aprendizagem Significativa em Revista/Meaningful Learning Review, v. 4(3), pp. 61-67, 2014.

MOREIRA, M. A. Aprendizagem significativa: a teoria e textos complementares. 1. ed. São Paulo: Livraria da Física, 2011.

MOREIRA, M. A. ¿Al final qué es aprendizaje significativo? Revista Qurriculum: revista de teoría, investigación y práctica educativa, La Laguna, Espanha, 2012, 25: 2956.

SILVA, S. C. R.; SCHIRLO, A. C. Teoria da Aprendizagem Significativa de Ausubel: reflexões para o ensino de Física ante a nova realidade social. Revista Imagens da Educação, v. 4, n. 1, p. 36-42, 2014.

SOUSA, A.T.O.; FORMIGA, N.S.; OLIVEIRA, S.H.S.; COSTA, M.M.L.; SOARES, M.J.G.O. A utilização da teoria da aprendizagem significativa no ensino da Enfermagem. Rev. Bras. Enferm. [online], 2015, vol. 68, n. 4, pp.713-722. ISSN 00347167. 